\title{
Virtual cathode emission of an annular cold cathode
}

\author{
S.-d. Park, ${ }^{*}$ J.-h. Kim, J. Han, M. Yoon, and S. Y. Park \\ Department of Physics, Postech, San 31, Hyoja-dong, Nam-gu, Pohang, Gyeongbuk 790-784, Republic of Korea \\ D. W. Choi, J. W. Shin, and J. H. So \\ Korean Agency for Defense Development (ADD), Jochiwongil 462, Yuseonggu, Daegeon 305-600, Republic of Korea
}

(Received 9 May 2009; published 17 November 2009)

\begin{abstract}
Recent measurement of voltage $V$ and current $I$ of the electron gun of a relativistic klystron amplifier revealed that the resulting current-voltage relationship appeared to differ from the usual Child-Langmuir law $\left(I \propto V^{3 / 2}\right)$ especially during the initial period of voltage increase. This paper attempts to explain this deviation by examining the emission mechanism using particle-in-cell simulation. The emission area in the cathode increased stepwise as the applied voltage increased and within each step the current and voltage followed the Child-Langmuir law. The electron emission began when the voltage reached a threshold, and the perveance increased with the emission area. Furthermore, an apparent virtual cathode was formed which was larger than the cathode tip. This occurs because, above a certain voltage, the emission from the edge and the side of the cathode surface dominates the emission from the front-end surface.
\end{abstract}

DOI: 10.1103/PhysRevSTAB.12.113502

PACS numbers: $84.70 .+\mathrm{p}, 41.20 .-\mathrm{q}, 41.60 .-\mathrm{m}$

\section{INTRODUCTION}

A high power microwave (HPM) source is a device which generates an intense electromagnetic wave such that it can disable electronic equipment. Among many devices which have been developed as HPM sources, the relativistic klystron amplifier (RKA) generates a wave of high power, wide bandwidth, high efficiency, and stable phase and amplitude. For RKA to be used in practice, it must emit an electromagnetic wave of very high power (of GW level) which is sufficient to damage a circuit. It also requires short pulse duration (of a few hundred ns) imposed by the energy-dissipation time of the circuit. RKA emits high power electron beams from the cathode and transforms them into a microwave by passing them through multiple cavities [1]. For efficient interaction, an annular cathode is required to generate an electron beam of several $\mathrm{kA}$. The annular electron beam has less space-charge effect than a solid beam. For operation in the space-charge limited (SCL) regime, a cold cathode gun is usually required.

In an electron gun operated in the SCL regime, the perveance is a figure-of-merit parameter which measures the extracted beam current for given anode-cathode (A-K) gap voltage. In one-dimensional approximation, the emitted current from a planar diode satisfies the ChildLangmuir law, $I=P V^{3 / 2}[2,3]$, where $I$ is the extracted beam current and $V$ is the applied A-K gap voltage. The perveance $P$ is a geometry-dependent quantity, which is inversely proportional to the square of the A-K gap distance. For a given two- or three-dimensional geometry, analytical calculation of the perveance is difficult to obtain

*dduckz@postech.ac.kr
$[4,5]$. We have therefore resorted to a computer simulation to model the annular cathode and to investigate its emission characteristics. As we show in this paper, models which included the edge emission yielded the perveance similar to experimental results [6].

In this paper, we demonstrate experimentally and numerically that the voltage-dependent perveance change of a cold cathode gun is due to the increase in the area from which electrons are emitted. We also calculate the threshold voltage for the cathode emission by using the voltage and current obtained from the experiment.

In our experiment, the SCL current estimated from the measured voltage was very close to the current measured by a beam-current monitor (BCM), but it revealed some differences, especially during the initial phase when the current increased. To analyze such a behavior, we performed a particle-in-cell (PIC) simulation by dividing the cathode of 2-mm thickness into meshes of $\leq 0.1 \mathrm{~mm}$, a size limited by computer capability. This simulation provided several quantities, including the voltage-dependent perveance of the cold cathode gun, the threshold voltage for emission, the rate of emission, and change in the emission area.

It was anticipated that, when voltage $\geq 500 \mathrm{kV}$ was supplied to the annular ring of the cold cathode gun, most of the electrons would be emitted from the frontend surface. However, the simulation result showed that the electric field formed by electrons emitted at the outer edge and the inner edge blocked the electric field in the front so that the threshold electric field for the front-end emission was not reached. Simulation also showed that the emitted electrons at the outer edge and the side were confined by applied magnetic fields and formed a virtual 


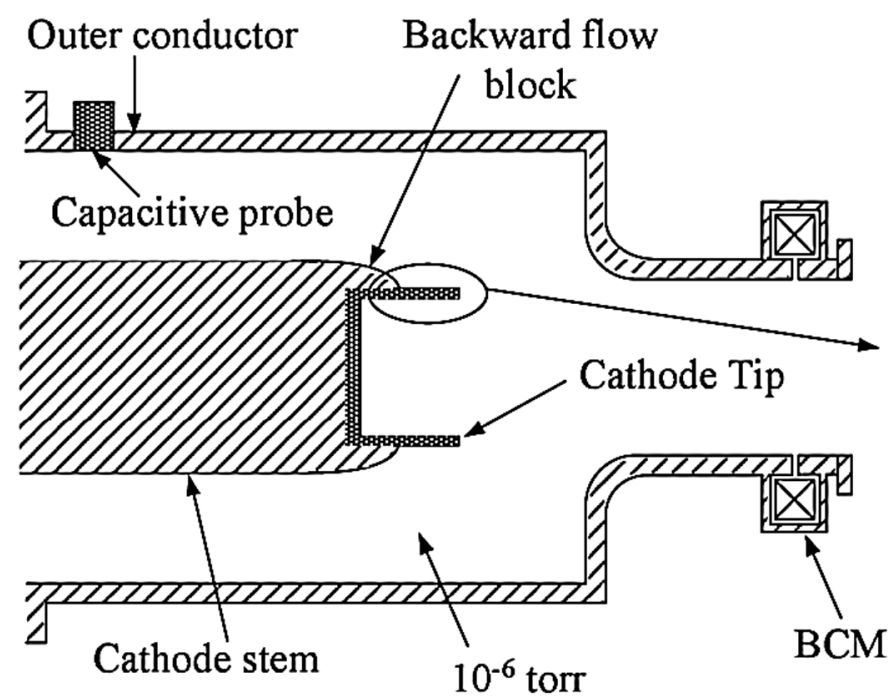

(a)

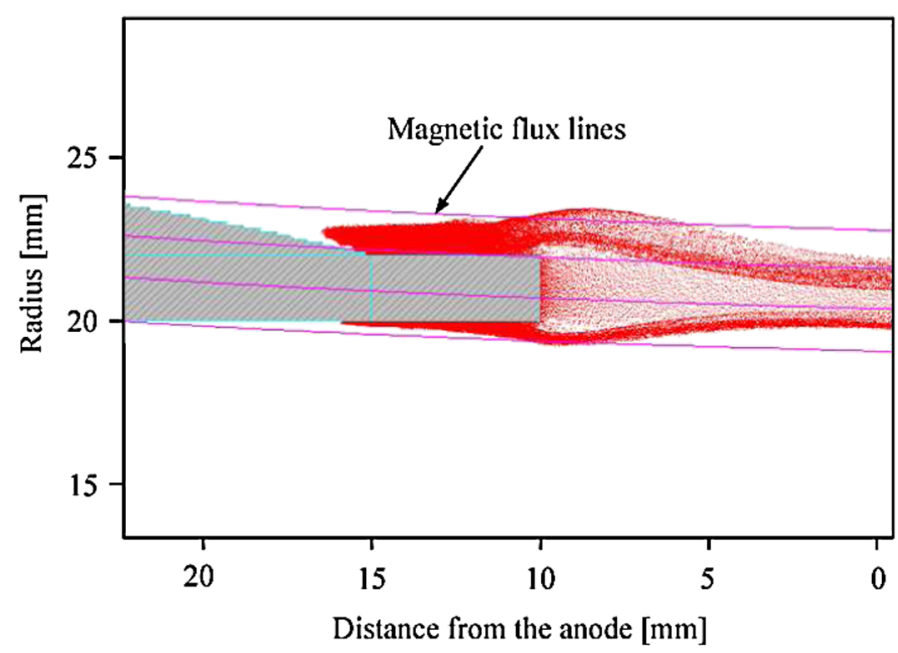

(b)

FIG. 1. (Color) (a) Cross section of the gun structure. (b) The beam trajectory at the cathode with full emission. All backward currents are blocked by the cathode holder. Magnetic field of $0.8 \mathrm{~T}$ was applied using ten pancake coils.

cathode which appeared to be an apparent increase in the emission area of the cathode tip.

This paper is organized as follows: in Sec. II we describe the experimental setup and experimental results showing the difference between the SCL current from the measured voltage and the current from BCM. In Sec. III, we explain the emission mechanism and the virtual cathode formation by analyzing the voltage and current of the cathode emission obtained by simulation in MAGIC2D [7] under the same conditions as used in the experiment. Section IV presents a summary and conclusion.

\section{EXPERIMENT}

In the RKA experiment, to match the Marx impedance which is a source of the voltage to $150 \Omega$, the A-K gap was set to $30 \mathrm{~mm}$. To maintain the clearance distance between the electron beam and the beam tube at $2 \mathrm{~mm}$, the cathode radius was set to $20-22 \mathrm{~mm}$.

The gun [Fig. 1(a)] includes a capacitive probe to measure the voltage supplied on the cathode and a BCM to read the emitted current. The cathode tip was made of high quality graphite (Poco Graphite Inc.) and the air pressure

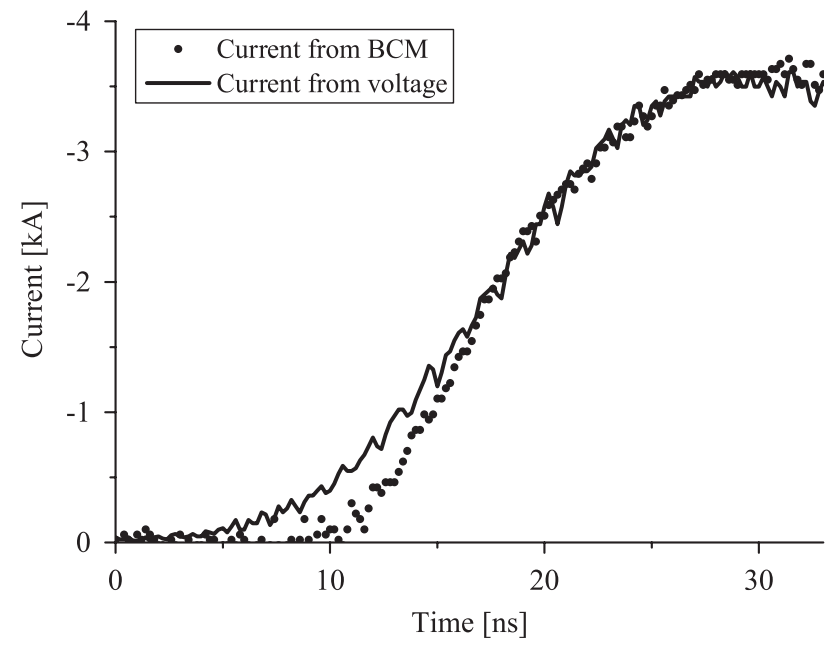

(a)

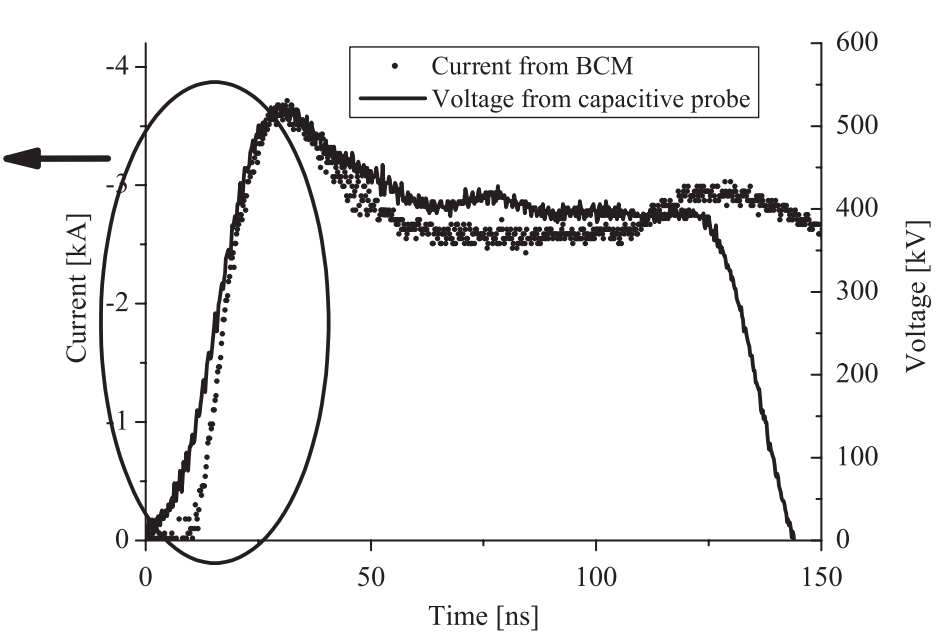

(b)

FIG. 2. (a) Comparison of the measured current (dots) with the space-charge limited current (curve) which was obtained from the applied voltage and the Child-Langmuir law with $9.8 \mu \mathrm{P}$ during $30 \mathrm{~ns}$ of rising time. (b) Voltage (vertical axis on the right-hand side) measured from the capacitive probe and the current (vertical axis on the left-hand side) from BCM for the supplied voltage with rising time of $30 \mathrm{~ns}$ and peak voltage of $530 \mathrm{kV}$. 


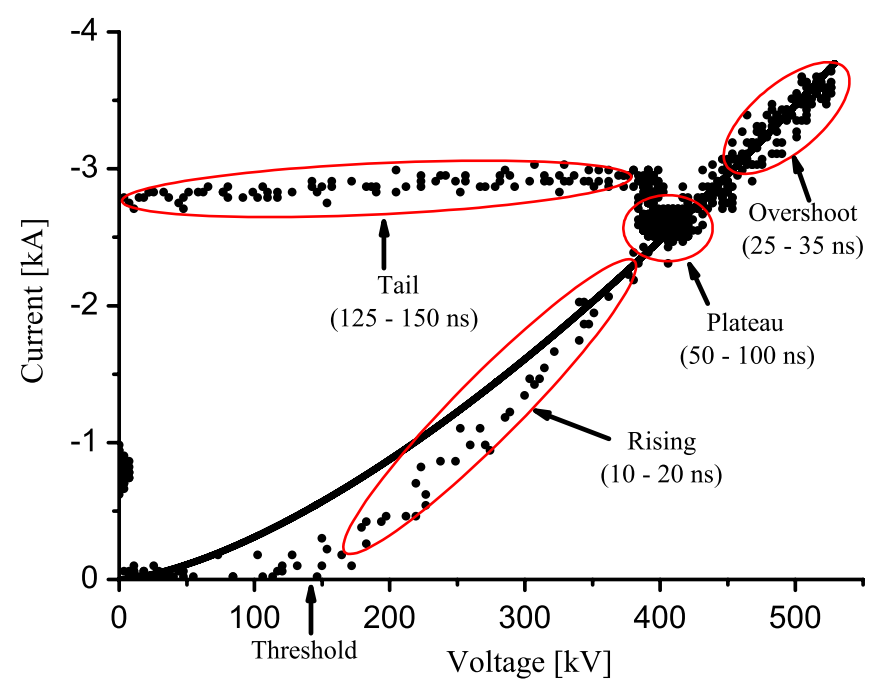

FIG. 3. (Color) Measured current from BCM with respect to the voltage measured by capacitive probe. Dots are the data measured from the experiment and the solid curve is the fitted result with the Child-Langmuir law. The perveance is $9.8 \mu \mathrm{P}$.

inside the gun was maintained at $10^{-6}$ torr to reduce plasma formation. The cathode holder is designed to block the backward leakage current due to the side emission as Fig. 1(b) shows. For beam guidance, a magnetic field of $0.8 \mathrm{~T}$ was applied using ten pancake coils.

Using the voltage probe and the current monitor, the beam current was measured as a function of the voltage which increased in time. The measured current and voltage both increased sigmoidally over time [Fig. 2(b)]; during the rise, peak, and plateau sections of the curves, the current variation follows the voltage change closely, but after $100 \mathrm{~ns}$ it differs noticeably, which is attributed to stray charges in the BCM. A noticeable difference between these two currents occurred during the first $20 \mathrm{~ns}$ of voltage rise [Fig. 2(a)]. For the first $10 \mathrm{ns,}$, emission did not occur when the voltage increased, and for the following $10 \mathrm{~ns}$ the emission current caught up with the SCL current, and finally the two values became approximately the same.

The BCM current as a function of the voltage was measured at the capacitive probe (Fig. 3). Three features are noticeable. First, the measured current does not satisfy $I \propto V^{3 / 2}$. No emission occurs below a threshold voltage $(\sim 140 \mathrm{kV})$. Second, the initiated current increases quasilinearly as the voltage increases. Finally, the measured current approaches the SCL current satisfying $I \propto V^{3 / 2}$. In the following section, these phenomena are examined in detail.

\section{MODELING AND ANALYSIS}

A Poisson simulation [8] was first used to visualize the electric field distribution for given constant A-K gap voltage. The cathode tip [Fig. 4(a)] was divided into meshes of $\leq 0.01 \mathrm{~mm}$. The magnitude of the electric field was obtained along the vertical line at $0.01-\mathrm{mm}$ distance from the cathode front when the A-K voltage was $140 \mathrm{kV}$, which was the approximate threshold voltage observed in the experiment (Fig. 3). The maximum value of the electric field was $300 \mathrm{kV} / \mathrm{cm}$ [Fig. 4(b)].

Then MAGIC2D simulation was used to investigate time-dependent emission properties. The cathode was represented by a mesh of $\leq 0.1 \mathrm{~mm}$ (limited by computer) and the field probing line was set to $0.1 \mathrm{~mm}$ away from the cathode tip. The "explosive emission" option was used in the simulation. In this option, a plasma is formed at the

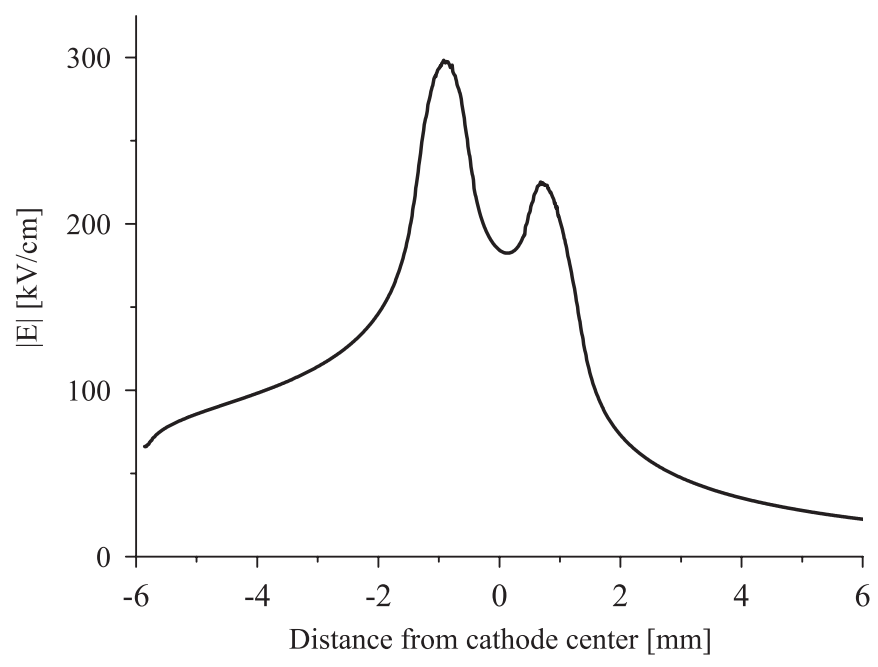

(b)

FIG. 4. (a) Cross section of the cathode. (b) The magnitude of the electric field at the cathode tip obtained with the Poisson code. The horizontal axis represents the distance along the vertical line at $0.01 \mathrm{~mm}$ from the cathode front. The A-K gap voltage is $140 \mathrm{kV}$. The cathode edge was rounded to $0.5 \mathrm{~mm}$ in radius which is the same as the real model. 
cathode after the emission occurs above the threshold voltage, so the emission occurs below the threshold voltage.
The electric fields along the probing line and the electron emission from the cathode were simulated at different times (voltages) [Figs. 5(a)-5(f)]. The difference in elec-
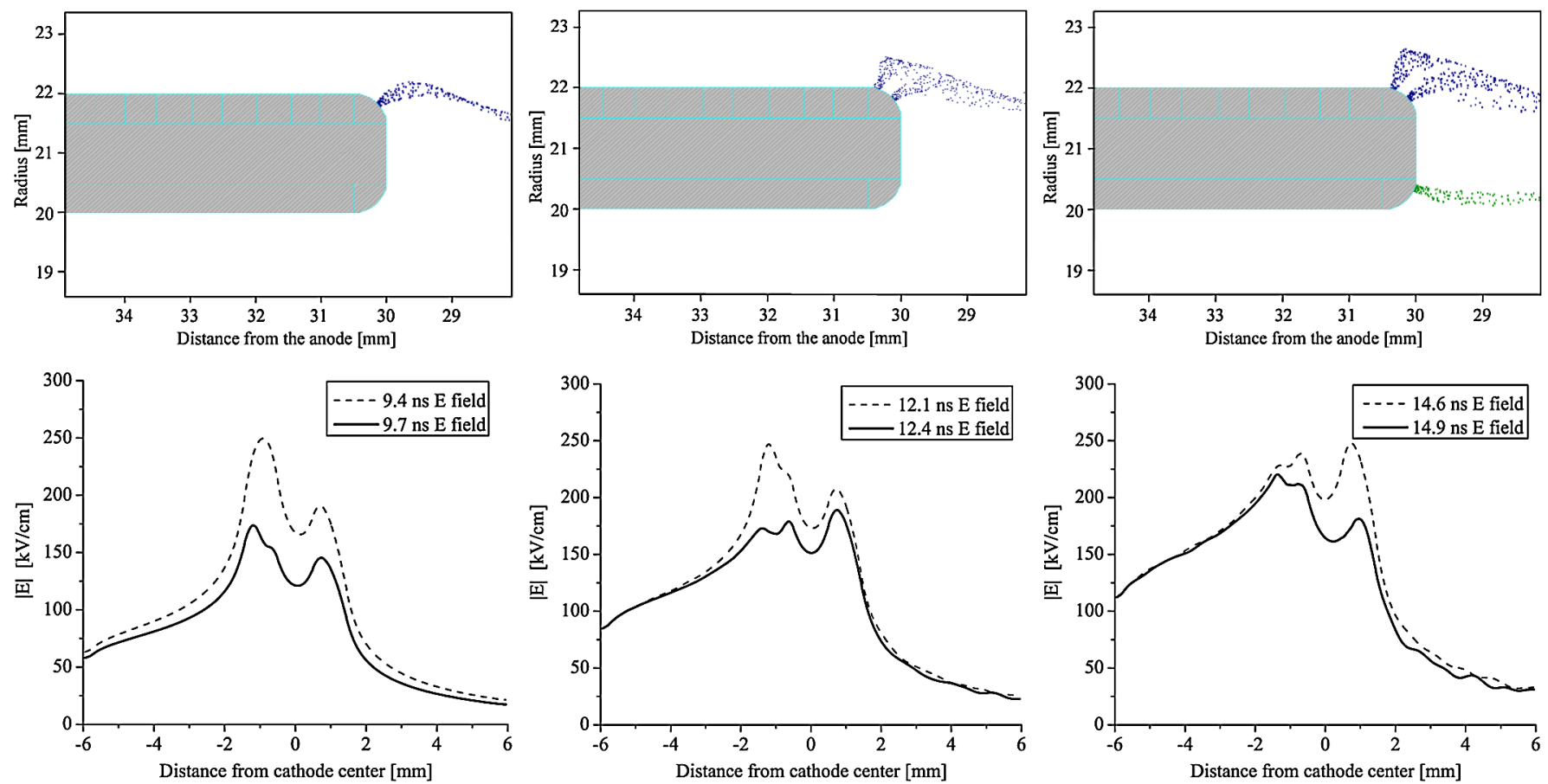

(a)

(b)
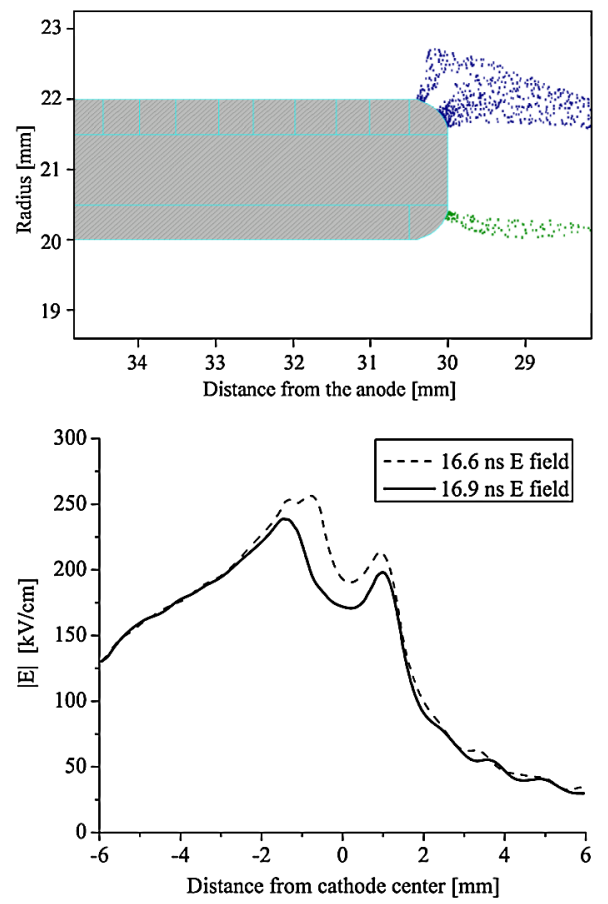

(d)

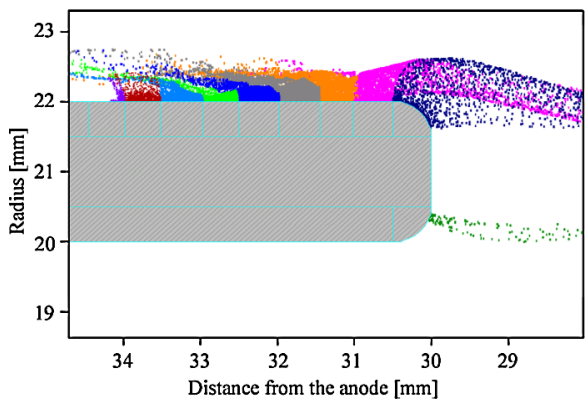

(c)

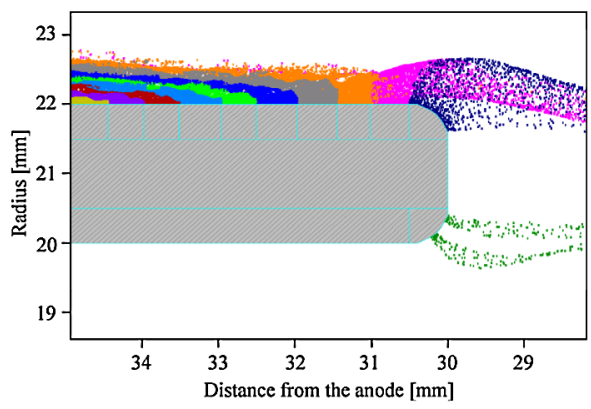

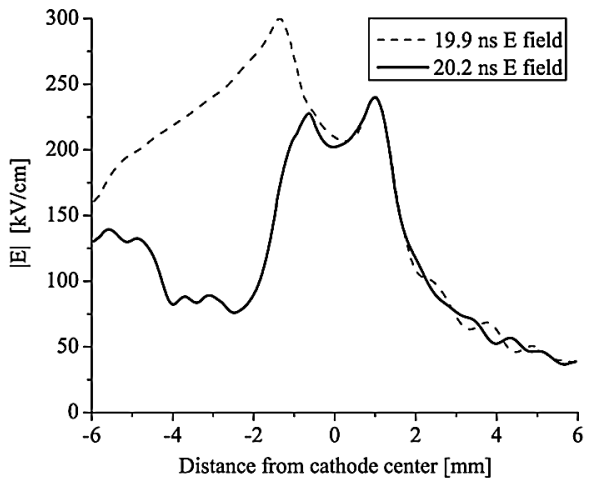

(e)

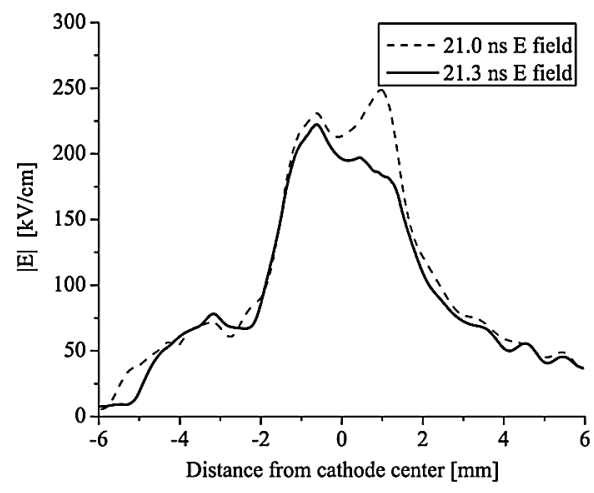

(f)

FIG. 5. (Color) Depression rate of the magnitude of the electric field and the emission area by the emission step. Each step represents the moment of the increase of the emission area. (a) 1 st step (140 kV) emission, (b) 2nd step (200 kV) emission, (c) 3rd step (250 kV) emission, (d) 4th step (310 kV) emission, (e) 5th step (400 kV) emission, and (f) 6th step (430 kV). 
tric fields between Fig. 5(a) and Fig. 4 is due to the different location of the field probing line.

Figures 5(a)-5(f) depict emissions occurring at six discrete times, after the electric field exceeds the threshold at the cathode tip. At the moment of the emission, the intensity of the electric field decreased suddenly, but because of the continuous increase in voltage the total electric field increased without further increase in the emission area. The emission initiated from the outer edge [Fig. 4(a)] at $140 \mathrm{kV}$ is larger than the emission from the inner edge and the outside, as the A-K gap voltage increases. Then at $250 \mathrm{kV}$ the emission from the inner edge began [Fig. 5(c)], etc. This process continued and into $530 \mathrm{kV}$ six different discrete emissions emanated at different locations.

Above $400 \mathrm{kV}$ A-K gap voltage the emission occurred at the side of the cathode, and some electrons traveled backward [Figs. 5(e) and 5(f)]. To block such an unwanted backward current, the radius of the cathode stem was set to $25 \mathrm{~mm}$ (larger than $22 \mathrm{~mm}$ ) and the magnetic flux line was designed to be flat. Trajectories of the beam obtained from MAGIC2D with these geometry changes revealed that backward-moving electrons are indeed blocked by the holder [Fig. 1(b)]. This was also verified by the experiment.

With the MAGIC2D simulation, the voltage and the current were also examined in the same place as in the RKA experiment; the simulation results agree well with experimental results (Fig. 6).

When a cold cathode gun operates in the SCL emission regime, the current-voltage curve satisfies the ChildLangmuir law and the perveance becomes a constant that depends on the geometry of the gun. But the I-V curve

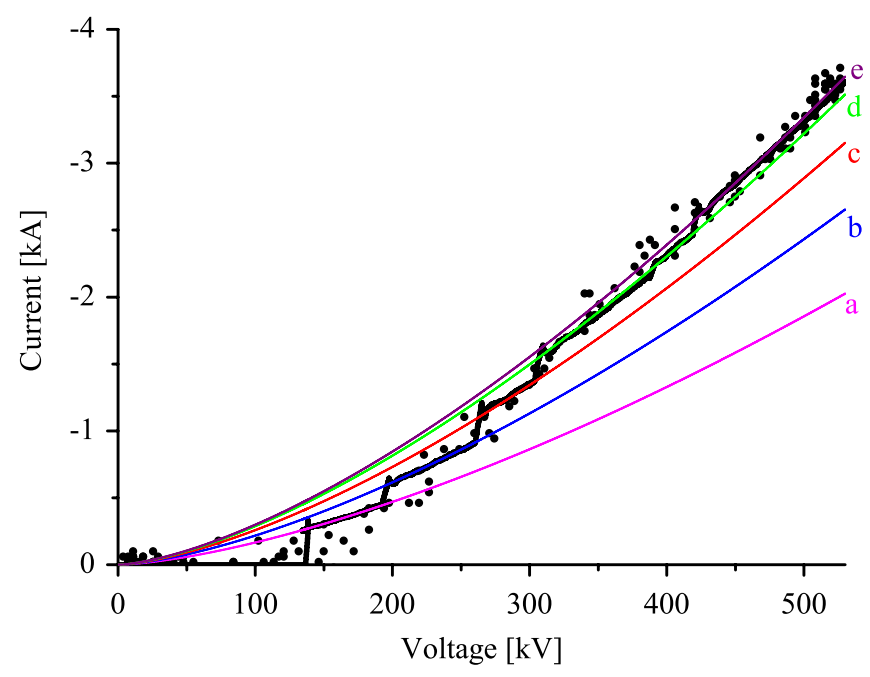

FIG. 6. (Color) Current expressed with respect to voltage. Dots are the measured result and the thick solid curve is the MAGIC2D result. Other solid curves represent the characteristic perveances satisfying Child-Langmuir law: (a) $5.25 \mu \mathrm{P}$, (b) $6.88 \mu \mathrm{P}$, (c) $8.17 \mu \mathrm{P}$, (d) $9.11 \mu \mathrm{P}$, and (e) $9.45 \mu \mathrm{P}$. obtained in our experiment shows a stepwise behavior where each section of the curve satisfies the ChildLangmuir law with different constant values of the perveance (Fig. 6). Simulation results suggest that this occurs because the increase of the voltage causes a stepwise increase in the emission area, and that the perveance also increases stepwise. Here the area increases stepwise because in the simulation the mesh size is not infinitesimal and the increase of the emission area is discrete.

To analyze the increase of the current in more detail, the cathode-tip region was divided into five sections (outside, outer edge, front, inner edge, inside) and the perveance of each section was evaluated while the voltage increased.

The perveance calculated from the total current (Fig. 7) increased with the voltage similar to the experimental result, but increased stepwise, which is again due to the discontinuous increase of the emission area. When in a specific section the emission area increases, the partial perveance in the section increases, while the perveances in the other sections decrease because the increase of the emission suppresses the electric field of the cathode tip (Fig. 5). However, the perveance increment in a specific cell is larger than the whole decrement in the others so the total perveance increases gradually as the voltage ramps up. For example (Fig. 7), the inner-edge area increases at $430 \mathrm{kV}$, and the corresponding perveance (b) increases sharply whereas the perveance (a) at the outer edge drops, but the increment is larger than the decrement.

The reason why the front emission did not occur up to the maximum voltage in the experiment is because of the electric depression due to the outer-edge and inner-edge emissions. The simulation was then performed on voltages up to $700 \mathrm{kV}$ to see the front emission.

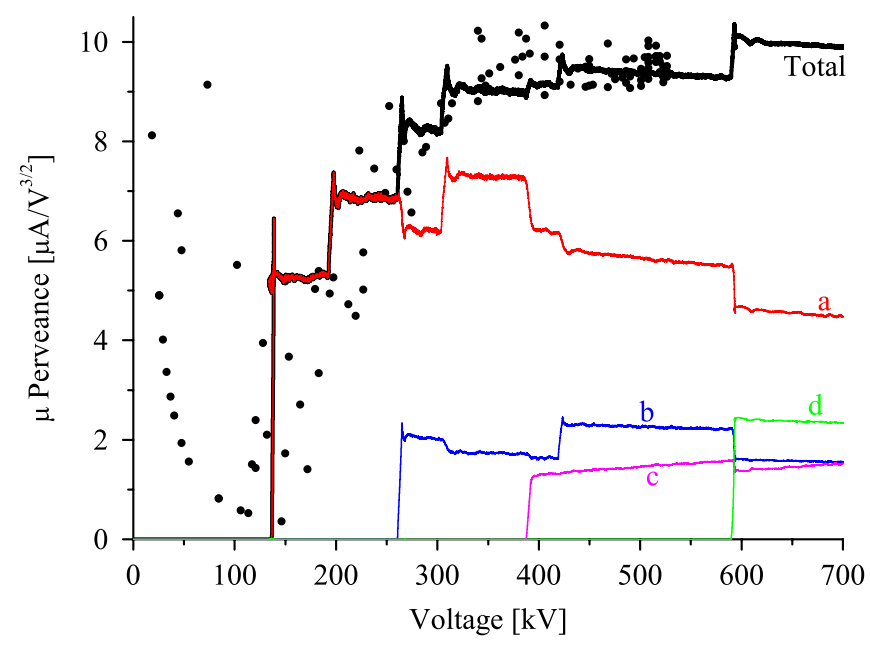

FIG. 7. (Color) Perveance with respect to voltage. The partial perveance and the total perveance compared to the experimental result. Dots represent the experimental perveance and the thick solid line is the perveance of total current. Other lines show the partial perveances of separated areas: (a) outer edge, (b) inner edge, (c) outside, and (d) front. 


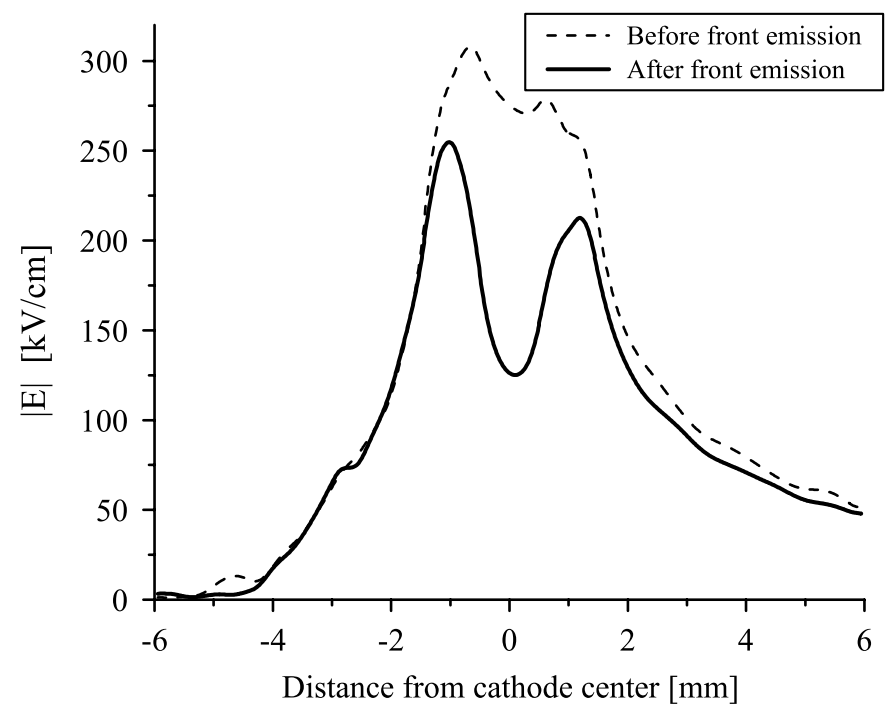

(a)

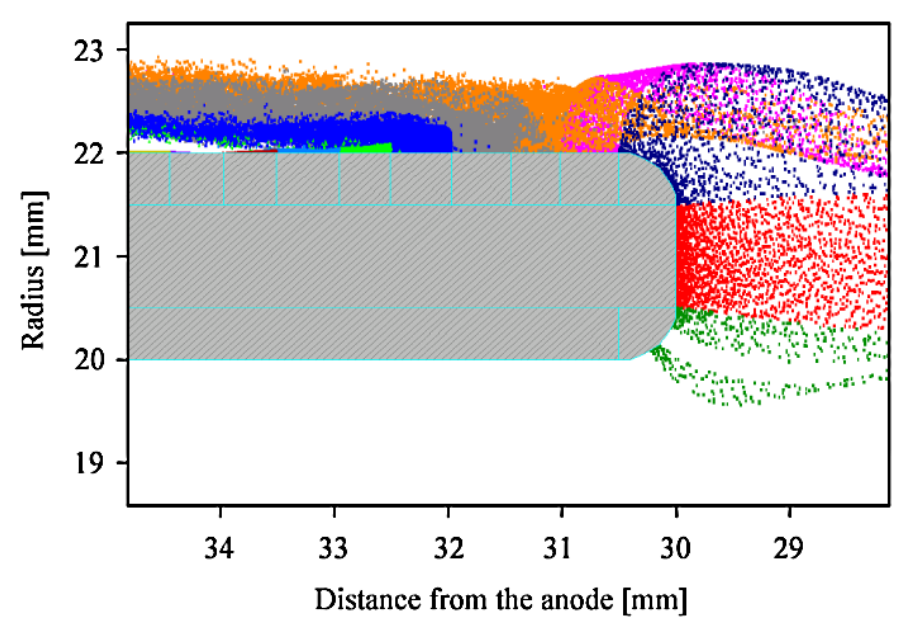

(b)

FIG. 8. (Color) The change in electric field when the front emission occurred (a) and the beam trajectory (b). The front emission occurred when the A-K gap voltage reached $600 \mathrm{kV}$.

The front emission occurred when the A-K gap voltage was $\geq 600 \mathrm{kV}$ and the magnitude of the electric field decreased considerably after the emission occurred (Fig. 8). The pattern of the electric field intensity is similar to the case before the emission at $140 \mathrm{kV}$ [Fig. 5(a)] because the current of the full emission suppresses the electric field.

When emission from the front-end surface occurred, the magnetic field is vertical, trajectories of the electrons emitted at the side and the edge get shifted toward the anode, making the width of the beam flux greater than the width of the cathode tip by about $1 \mathrm{~mm}$ [Fig. 8(b)]. We call this the virtual cathode emission. The emission occurs in a larger area than the actual size of the cathode tip. (The meaning of "virtual cathode" here is different from those used in Refs. [9,10].)

The perveance was simulated with $(600 \mathrm{kV})$ and without $(530 \mathrm{kV})$ the front emission (Table I), and these values were used to calculate the ratios of the partial perveances to total perveances.

In the MAGIC2D code, the cathode tip [Fig. 9(a)] was divided into meshes of $0.1 \mathrm{~mm}$ and emission was simulated at the front emission area without edge cells [Fig. 9(b)], at the front emission area with edge cells [Fig. 9(c)], and at

TABLE I. Partial perveances before and after the front emission in MAGIC2D simulation.

\begin{tabular}{lccccc}
\hline \hline $\begin{array}{l}\text { A-K gap } \\
\text { Voltage }\end{array}$ & $\begin{array}{c}\text { Outer-edge } \\
\text { perveance }\end{array}$ & $\begin{array}{c}\text { Inner-edge } \\
\text { perveance }\end{array}$ & $\begin{array}{c}\text { Outside } \\
\text { perveance }\end{array}$ & $\begin{array}{c}\text { Front } \\
\text { perveance }\end{array}$ & $\begin{array}{c}\text { Total } \\
\text { perveance }\end{array}$ \\
\hline $\mathrm{kV}$ & $\mu \mathrm{P}^{\mathrm{a}}$ & $\mu \mathrm{P}$ & $\mu \mathrm{P}$ & $\mu \mathrm{P}$ & $\mu \mathrm{P}$ \\
\hline 530 & $5.70(60.6 \%)$ & $2.32(24.6 \%)$ & $1.43(14.8 \%)$ & 0 & 9.45 \\
600 & $4.48(46.3 \%)$ & $1.61(15.9 \%)$ & $1.37(13.6 \%)$ & $2.44(24.2 \%)$ & 10.1 \\
\hline \hline & & & &
\end{tabular}

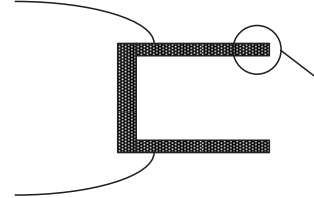

(a)

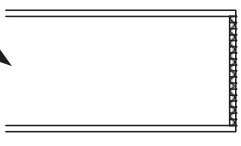

(b)

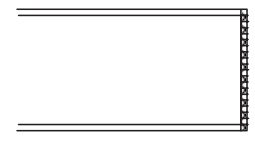

(c)

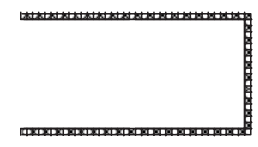

(d)

FIG. 9. Emission area used in the MAGIC2D simulation. (a) Schematic geometry of the cathode tip. (b) Only front emission was allowed. (c) Both front and edge emissions were allowed. (d) All front, edge, and side emissions were allowed. 
TABLE II. Comparison of perveances predicted by MAGIC2D simulation at an A-K gap voltage of $500 \mathrm{kV}$. The values with superscript $*$ denote the perveances at $600 \mathrm{kV}$.

\begin{tabular}{|c|c|c|c|c|}
\hline $\begin{array}{l}\text { A-K gap } \\
\text { distance } \\
\text { mm }\end{array}$ & $\begin{array}{l}\text { Cathode } \\
\text { tip } \\
\text { radius } \\
\text { mm }\end{array}$ & $\begin{array}{c}\text { Front } \\
\text { [Fig. 9(b)] } \\
\text { perveance } \\
\quad \mu \mathrm{P}\end{array}$ & $\begin{array}{l}\text { Front and } \\
\text { edge } \\
\text { [Fig. } 9(\mathrm{c})] \\
\text { perveance } \\
\mu \mathrm{P}\end{array}$ & $\begin{array}{c}\text { Front, edge, } \\
\text { and side } \\
\text { [Fig. } 9(\mathrm{~d})] \\
\text { perveance } \\
\mu \mathrm{P}\end{array}$ \\
\hline \multirow[t]{2}{*}{10} & $19-21$ & 17.4 & 19.8 & 19.8 \\
\hline & $20-22$ & 19.2 & 22.0 & 22.0 \\
\hline \multirow[t]{2}{*}{30} & $19-21$ & 8.85 & 9.67 & $8.54(9.55)^{*}$ \\
\hline & $20-22$ & 9.35 & 10.2 & $9.06(10.1)^{*}$ \\
\hline
\end{tabular}

the front emission area with both edge cells and the side emission [Fig. 9(d)].

To design a cold cathode gun at the A-K gap voltage of $500 \mathrm{kV}$, considering the Marx impedance, we set the A-K gap distances as 10 and $30 \mathrm{~mm}$ and, to maintain the clearance of $2 \mathrm{~mm}$ between the emitted current and the beam tube of radius $23 \mathrm{~mm}$, we set the radii of the cathode tip as $19-21 \mathrm{~mm}$ and $20-22 \mathrm{~mm}$. Perveances were determined by the difference of the emission areas of the MAGIC2D code at the A-K gap voltage of $500 \mathrm{kV}$ (Table II). When the edge emission was included, the perveance increased by $10 \%$ and became almost the same as the experimental result. When the A-K gap was $10 \mathrm{~mm}$, the perveance did not change with the addition of the side emission. However, when the A-K gap was $30 \mathrm{~mm}$, the perveance decreased because the front emission was suppressed by the electric field depression due to the side emission.

Analysis using the virtual cathode in the simulation revealed one noteworthy result. When the A-K gap distance was $10 \mathrm{~mm}$, inclusion of the side emission had no effect on perveance (Table II), which implies that the virtual tip has the same size regardless of the side emission. However, this does not imply that the side emission can be ignored in the simulation. This is because at some A-K gap voltage the addition of the side emission suppresses the front emission so that the perveance has a different value from that expected in the full emission. For example, when the A-K gap distance was $30 \mathrm{~mm}$ and the A-K gap voltage was $500 \mathrm{kV}$, the perveance of the front and the edge emission decreased from 10.2 to $9.06 \mu \mathrm{P}$ after the addition of the side emission (Table II).

One important result of the simulation should be emphasized. For the rectangular tip [Fig. 9(d)] with the A-K gap distance $30 \mathrm{~mm}$, full emission occurred at $600 \mathrm{kV}$. In that case, the perveance became $9.55 \mu \mathrm{P}$ for tip radius 19 $21 \mathrm{~mm}$ and $10.1 \mu \mathrm{P}$ for tip radius $20-22 \mathrm{~mm}$, which is almost the same as the perveance of the full emission for the rounded tip. This is consistent with the result that the sizes of the virtual tips are almost the same for both the rectangular and the rounded cases.

\section{CONCLUSIONS}

To analyze the voltage and the current characteristics in the RKA experiment, we examined the emission mechanism of threshold electric field using MAGIC2D and Poisson simulations. During the first $30 \mathrm{~ns}$ of voltage increase, the perveance of the cold cathode gun was determined by the emission area, and the partial perveance of a specific area was also affected and determined by the emission from other areas. The current-voltage relationship seems not to satisfy the Child-Langmuir law but instead current increases quasilinearly starting from the threshold voltage in a specific cathode tip. However, simulation reveals that the current actually satisfies the law in that it increases stepwise and that during each step it satisfies the Child-Langmuir curve with different constant perveances. In particular, the currents emission from the edge and the side was verified by the MAGIC2D simulation of the virtual cathode emission which appears in the area larger than the cathode width. The simulated currents corresponding to the input voltages agreed with the experimental value.

\section{ACKNOWLEDGMENTS}

This work was supported by the BK21 program of the Korean Ministry of Education, Science and Technology (MEST). The Marx generator and RKA were built in the Pohang Accelerator Laboratory.

[1] M. V. Fazio, W. B. Haynes, B. E. Carlsten, and R. M. Stringfield, IEEE Trans. Plasma Sci. 22, 740 (1994).

[2] C. D. Child, Phys. Rev. (Series I) 32, 492 (1911).

[3] I. Langmuir, Phys. Rev. 2, 450 (1913).

[4] R. J. Umstattd and J. W. Luginsland, Phys. Rev. Lett. 87, 145002 (2001).

[5] Y.M. Saveliev, W. Sibbett, and D. M. Parkers, J. Appl. Phys. 94, 5776 (2003).

[6] R. K. Parker, J. Appl. Phys. 45, 2463 (1974).

[7] B. Goplen, L. Ludeking, D. Smithe, and G. Warren, Comput. Phys. Commun. 87, 54 (1995).

[8] J.H. Billen and L.M. Young, Los Alamos National Laboratory Report No. LA-UR-96-1834, 2004.

[9] A. I. Fedosov, E. A. Litvinov, S. Ya. Belomyttsev, and S. P. Bugaev, Izv. Vyssh. Uchebn. Zaved., Fiz. 10, 134 (1977).

[10] S. Ya. Belomyttsev, A. A. Grishkov, S. A. Kitsanov, S. D. Korovin, S. D. Polevin, and V. V. Ryzhov, Tech. Phys. 31, 55 (2005). 